\title{
Editorial
}

\section{Vacinação: direito individual ou coletivo?}

Editorial

Vaccination: individual or collective right?

Editorial

Vacunación: ¿derecho individual o colectivo?

\section{Sandra Mara Campos Alves ${ }^{1}$ \\ Maria Célia Delduque ${ }^{2}$ \\ Marcelo Lamy ${ }^{3}$}

O mundo observa atentamente o processo de corrida em busca do desenvolvimento da vacina contra o coronavírus. Segundo documento elaborado pela Organização Mundial da Saúde (OMS), de 9 de setembro de 2020, há nove vacinas que já se encontram na fase III dos estudos (1). Se aprovada, a vacina segue para a fase de registro sanitário e aprovação para comercialização pelas autoridades competentes. No caso brasileiro, essa competência é atribuição da Agência Nacional de Vigilância Sanitária (Anvisa).

O controle epidemiológico de doenças transmissíveis por meio da vacina representou uma grande revolução na ciência e na história da saúde pública. A descoberta da primeira vacina, no ano de 1796, pelo médico inglês Edward Jenner, se deu para combater a epidemia de varíola (2). Considerada um grande flagelo, estima-se que a varíola foi responsável por cerca de 40 milhões de mortes em todo o mundo durante o século XVIII, apresentando uma taxa de letalidade que variava entre $20 \%$ a $40 \%$, e os sobreviventes podiam apresentar sequelas severas, tais como desfigurações, cegueira e esterilidade (2) (3). A varíola, até hoje é a única doença que foi mundialmente erradicada.

Contudo, a vacinação, apesar de se constituir em uma medida de saúde simples, foi bastante combatida desde sua concepção, ocasião em que se observa o surgimento dos primeiros movimentos antivacinação, a partir da promulgação de leis inglesas que tornava a

\footnotetext{
${ }^{1}$ Doutora; pesquisadora, Programa de Direito Sanitário (Prodisa), Fundação Oswaldo Cruz, Brasília, Distrito Federal, Brasil. https://orcid.org/0000-0001-6171-4558. E-mail: smcalves@gmail.com

2 Doutora; pesquisadora, Programa de Direito Sanitário (Prodisa), Fundação Oswaldo Cruz, Brasília, Distrito Federal, Brasil. https://orcid.org/0000-0002-5351-3534. E-mail: mcdelduque@gmail.com

3 Doutor em Direito Constitucional, Pontifícia Universidade Católica (PUC), São Paulo, SP, Brasil; professor permanente e vice-coordenador, Programa de Pós-Graduação em Direito da Saúde, Universidade Santa Cecília (Unisanta), Santos, São Paulo, Brasil. http://orcid.org/0000-0001-8519-2280. E-mail: marcelolamy@unisanta.br
} 
vacinação compulsória para adultos e crianças (4). No Brasil, a vacinação obrigatória contra a varíola levou à deflagração do episódio conhecido como Revolta da Vacina, em 1904 (4).

Atualmente, o tema voltou a ganhar relevo, especialmente após o Supremo Tribunal Federal (STF) reconhecer, por unanimidade, Repercussão Geral - Tema 1.103 - no recurso que discute se os pais podem deixar de vacinar seus filhos, tendo como fundamentos convicções filosóficas, religiosas, morais e existenciais (5).

Questiona-se, no aludido recurso extraordinário, a amplitude da imposição estabelecida pelo artigo 14, §1ํㅡ, do Estatuto da Criança e do Adolescente, Lei nº 8.069/1990 -à obrigatoriedade da vacinação das crianças nos casos recomendados pelas autoridades sanitárias, cujo descumprimento pode implicar sanção administrativa pecuniária (art. 249). (5)

Ocorre que a questão afeta tanto o direito individual à saúde de cada criança, quanto o direito coletivo à saúde, visto tratar-se também de uma política sanitária preventiva de doenças, cuja desobediência pode vir a configurar crime contra a saúde pública, nos termos do artigo 268 do Código Penal, Decreto-Lei no 2.848/1940.

A diferença de reação estabelecida pelo ordenamento jurídico diante da infração individual (administrativa, pecuniária) e da infração coletiva (criminal) desvela norte para interpretar a questão.

Segundo o Min. Roberto Barroso, relator da ação, o ponto nodal consiste na definição dos contornos das relações entre Estado e família, visto que, se de um lado os pais têm direitos e liberdades na condução da criação dos filhos conforme suas escolhas e orientações ideológicas e religiosas, por exemplo, por outro lado, o Estado também tem o dever de proteção não apenas das crianças, mas de todo a coletividade, sendo a vacinação, uma das medidas sanitárias usadas com esse desiderato. (5)

O relator destaca ainda que a repercussão geral se dá nos aspectos social, político e jurídico, a saber:

(i) social, em razão da própria natureza do direito pleiteado e da importância das políticas de vacinação infantil determinadas pelo Ministério da Saúde; (ii) político, tendo em conta o crescimento e a visibilidade do movimento antivacina no Brasil, especialmente após a pandemia da Covid-19, o que tem contribuído para diminuir a cobertura imunológica da população brasileira; e (iii) jurídico, porque relacionado à interpretação e alcance das normas constitucionais que garantem o direito à saúde de crianças e da coletividade, bem como a liberdade de consciência e crença. (5) 
A saúde é bem jurídico que está diretamente relacionado com o atendimento das necessidades humanas básicas e, como tal, relaciona-se ao gozo de uma vida digna. Enquanto um direito social, a saúde responde pelo "fornecimento dos recursos fáticos indispensáveis ao efetivo exercício das liberdades e dos demais direitos fundamentais, buscando assegurar a liberdade efetiva pela igualdade material." (6)

A oferta de vacinação pelo ente público é uma ação positiva voltada à proteção da vida e da saúde, nas dimensões individual e coletiva. Contudo, o sucesso ou insucesso desse tipo de medida sanitária, de natureza preventiva, está diretamente relacionada à adesão da sociedade, pois a imunização tem o efeito direto de proteção individual, mas também atua de modo a elevar a proteção da comunidade em que o indivíduo habita, a chamada imunidade de rebanho (herd protection) (7). Ou seja, "se o efeito protetor do rebanho reduzir suficientemente o risco de infecção entre os não infectados, a infecção não será mais sustentável na população e a infecção será eliminada" ${ }^{4}$ (7). Essa imunização coletiva pode ser alcançada por meio de infecção prévia da população, provocada por um surto ou epidemia, ou pela vacinação. Em ambos os casos, para que a proteção coletiva ocorra é necessário que $80 \%$ da população esteja imune (7).

Assim, a recusa em aderir às campanhas de vacinação não afeta apenas a órbita individual, podendo apresentar impactos severos na saúde de toda uma coletividade, pois, se a cobertura vacinal não for suficiente para garantir a imunização da população, o risco de recrudescimento das doenças é real. Um exemplo dessa situação foi observado em 2019, quando o Brasil perdeu o reconhecimento concedido pela Organização Pan-Americana da Saúde (OPAS/OMS) de zona livre de sarampo em virtude da confirmação de casos novos contraídos dentro do próprio território (endêmicos) (4), ocasião em que o Ministério da Saúde se pronunciou no sentido de adotar medidas para elevar as taxas de cobertura vacinal para controlar a situação.

Do exposto é que se conclui que de nada servirão os avanços da medicina na pesquisa e desenvolvimento de novas vacinas se não houver uma adesão coletiva da sociedade. De outra parte, o Estado não pode apenas esperar que essa adesão se dê de modo consciente e voluntário, por vezes, terá que fazer valer do seu dirigismo para proteger o direito à saúde.

\footnotetext{
4 Tradução livre.
} 


\section{Referências}

1. Organização Mundial da Saúde. Draft landscape of COVID-19 candidate vacines. 2020 [Acesso em 13 de set 2020]. Disponível em https://www.who.int/publications/m/item/draftlandscape-of-covid-19-candidate-vaccines

2. Friedman M, Friedland GW. As dez maiores descobertas da medicina. São Paulo: Companhia das Letras; 2006.

3. Simmons JG. Médicos e Descobridores: vidas que criaram a medicina de hoje. Rio de Janeiro: Record; 2004.

4. Pinto Junior VL. Antivacinação, um movimento com várias faces e consequências. Cadernos Ibero-Americanos de Direito Sanitário. 2019 abr./jun. [Acesso em 13 de set 2020]; 8(2):116-122. Disponível em:

https://www.cadernos.prodisa.fiocruz.br/index.php/cadernos/article/view/542

5. Supremo Tribunal Federal. Recurso Extraordinário com Agravo - ARE 1.267.879. [Acesso em 13 de set 2020]. Disponível em:

http://portal.stf.jus.br/processos/detalhe.asp?incidente $=5909870$

6. Figueiredo MF. Direito Fundamental à Saúde: parâmetros para sua eficácia e efetividade. Porto Alegre: Livraria do Advogado Editora; 2007.

7. Smith PG. Concepts of herd protection and immunity. Procedia in Vaccinology. 2010 [Acesso em 13 de set 2020]; 2(2): p.134-139. Disponível em:

https://reader.elsevier.com/reader/sd/pii/S1877282X10000299?token=B84D64CCE884E78 B763D08EE4F1762198AA2DDDD5B1B8D7FE871DE8EBB7945A9CD731B1D4786002018 36EC748955F3AA

Alves SMC, Delduque MC, Lamy M. Vacinação: direito individual ou coletivo? Cadernos Ibero-Americanos de Direito Sanitário. 2020 jul./set.; 9(3): 08-11.

http://dx.doi.org/10.17566/ciads.v9i3.737 